\title{
EDUCACIÓN EN LOS MÁRGENES. LA INICIATIVA JC:HEM ${ }^{1}$
}

Carlos Ballesteros*

\section{ANTECEDENTES}

En 2010 la Compañía de Jesús lanzó un nuevo proyecto que combinaba en su seno dos de las áreas donde los jesuitas tienen mayor presencia, recorrido y saber hacer: la educación, más en concreto la universitaria, y el trabajo con los refugiados a través de SJR. Así, varias universidades norteamericanas - luego se ampliaría el escenario- empezaron a ofrecer cursos de diversa índole para refugiados en Malawi, Kenia y Siria (ahora trasladados a Jordania) con el fin de proporcionar titulación universitaria a personas que viven en campos de refugiados y que a través de esta iniciativa pueden mejorar sus capacidades. Siguiendo los principios de la pedagogía ignaciana: Competencia - formación de calidad, personas competentes en su área-, Compasión- empatía, saber ponerse en el lugar del otro- y Conciencia - formar personas para los demás, formar agentes de cambio- y bajo la idea de primero experimentar, luego reflexionar y finalmente actuar se diseñó un diploma de un año en liberal arts y una serie de cursos dentro de una amplia línea de servicios a la comunidad.

A lo largo de estos cuatro años más de 750 personas de 20 países diferentes han visto cómo sus perspectivas de vida se ampliaban gracias a esta iniciativa que recibe el nombre de «Jesuit Commons: High Education at the Margins». El JC:HEM es una iniciativa que

Profesor de la Universidad Pontificia Comillas.

1 http://www.jc-hem.org/ 
trabaja, como su propio nombre indica «en los márgenes» y por eso comenzó en dos campos de refugiados africanos: Dzakela (Malawi) y Kakuma (Kenya).

- Dzaleka, en Malawi, fue originalmente pensado para dar respuesta a los conflictos en Mozambique, hace ya más de 20 años. Tras la decisión del gobierno de Malawi de cerrar los otros campamentos de refugiados en el país en 2007, Dzaleka es el único campo de la región que da soporte actualmente a los aproximadamente 10.000 refugiados consecuencia de diversos conflictos en África meridional y oriental, la Región de los Grandes Lagos, la República Democrática del Congo, Ruanda, Burundi, Uganda, Etiopía y Somalia.

- El campo de Kakuma (que en swahili significa «ninguna parte») fue establecido en 1992 para dar cabida a los sudaneses del sur que huían de la guerra civil, aunque actualmente el campamento también da cabida a refugiados de Somalia, la República Democrática del Congo, Burundi, Etiopía y Ruanda. Durante muchos años los sudaneses fueron el grupo más grande llegando a alcanzar los 60.000. Tras los acuerdos de paz de 2005 entre el Sudán Liberation Army/Movement (SPLA/M) y el gobierno sudanés, este equilibrio ha cambiado debido a la repatriación de éstos. Se calcula que para junio de 2009 aproximadamente 45.000 refugiados sudaneses habían regresado a Sudán. La población sudanesa en gran medida está siendo reemplazada por somalíes en respuesta a la afluencia de refugiados que huían de la guerra de clanes en su país, el

Casi enseguida el proyecto se amplió para dar atención a los refugiados sirios en Aleppo (Siria), en este caso no en un campo de refugiados al uso -que no existe- sino en la sede del Servicio Jesuita a refugiados de esa ciudad, que atiende a refugiados del medio oriente: sirios e iraquíes principalmente. En 2014 se abrió un nuevo centro JC: HEM en Herat, también con carácter urbano, que atiende a población Buthanesa, India y de Sri Lanka, mayoritariamente. En estudio está la expansión a Chad, Bhurma, Mae Hong Son (Tailandia) o Amman, (Jordania) en los cuales se ha empezado a impartir algun curso suelto Este último centro está recogiendo la población que va escapando de Aleppo. 


\section{SISTEMA EDUCATIVO}

Actualmente se ofrecen dos tipos de cursos: el CLST (Community Learning Service Tracks) que consisten en cursos de carácter práctico y profesionalizante para la vida en los campos de refugiados y el Diploma en Liberal Arts, de carácter más académico ( 45 créditos, 15 asignaturas, 3 años) otorgado por Regis University.

El CLST con un claro enfoque hacia la formación profesional para el trabajo con la comunidad, supone cursar 150 horas de diferentes itinerarios entre los que podrían destacar Proteccion a la infancia y participación, Servicios de apoyo a los negocios comunitarios, Formación de profesores de lengua inglesa o Mediacion y conflictos.

El Diploma, con una vocación reflexiva y académica se otorga cuando los alumnos han superado, durante dos años mínimo, asignaturas como Historia Mundial, Religiones, Informática, ética y filosofía, Pensamiento cuantitativo, Literatura mundial, negocios y desarrollo económico, pensamiento político, lectura y escritura multidisciplinar, métodos de investigación etc.

En 2015 se espera además poder desarrollar un Certificado de Enseñanza en los Márgenes, destinado a l profesorado que toma parte en esta iniciativa.

El sistema empleado es un sistema con gran base tecnológica. Los alumnos acuden a un centro de recursos pedagógicos (un barracón en los campos, la sede del SJR en Aleppo o Herat) donde tienen acceso a ordenador y conexión a internet, además de una pequeña biblioteca. Esto, que parece obvio, es especialmente dificultoso en campos como Kakuma, donde la principal fuente de electricidad se produce por paneles fotovoltaicos y por lo tanto solo puede usarse de día; donde la arena de la zona semidesértica (esto también aplica en Aleppo y Dzakela) se cuela en los equipos y los estropea. Además, acudir todos los días al centro no es tan fácil para una población que vive muy alejada del mismo (el campo de Kakuma es inmenso, cerca de 35 kilómetros cuadrados) y sólo pueden ir andado y que debe luchar por su supervivencia y la de su familia, a pesar de la ayuda internacional.

En cada centro hay una serie de tutores facilitadores, muchos de ellos también refugiados, que guían, tutelan, motivan, controlan y en definitiva llevan el día a día. Remotamente, un claustro de más de 160 profesores de diversas Universidades —fundamentalmente 
Norteamericanas, pero también españolas, mexicanas, colombianas o de Singapur - preparan en equipos de tres o cuatro profesores un temario de su disciplina y una metodología que incluye lecturas de fácil acceso, casos a resolver individualmente o en equipo, preguntas para foros de discusión, etc. Estos profesores, en continuo contacto con el equipo de facilitadores en terreno, se conectan como mínimo una vez a la semana durante las 8 semanas que dura un módulo e interactúan con los alumnos, contestan dudas o proponen nuevas discusiones, a la vez que corrigen los ejercicios previamente encargados.

\section{APRENDIZAJES DE LA EXPERIENCIA}

Participar en JC:HEM es una experiencia gratificante en muchos sentidos. En primer lugar, profesionalmente supone entrar en contacto con otros profesores de tu disciplina con los que intercambiar, compartir y en último término diseñar un curso. Si el roce hace el cariño este trabajo codo con codo proporciona además oportunidades de investigación conjunta, publicaciones, intercambio de materiales e incluso visitas académicas.

Una segunda experiencia gratificante es entrar en contacto con un alumnado diverso, que ha pasado y pasa dificultades y que a pesar de su, generalmente, altísima motivación debe ser cuidado y animado para que vayan realizando sus tareas y ejercicios en plazo. Estos alumnos son ordinariamente aplicados pero a veces su historia y circunstancia les hace en cierto modo demandantes de una atención paternalista que ellos mismo fomentan y explotan y que no está en ningún momento contemplada en el rigor ni el nivel que un curso universitario requiere.

El alumnado es multicultural en todos los sentidos. Cada curso (del diploma) se da simultáneamente en todos los centros, por lo que un reto para el profesor es atender esta diversidad y personalizar que detrás del nombre en la pantalla del ordenador hay personas en Siria, Malawi, Kenya o Jordania. Además en cada localización, la composición de los grupos es multiétnica. El cuidado a las diferentes sensibilidades unido a dificultades de carácter más práctico a la hora de establecer citas para chats o plazos de entrega (en los países mayoritariamente musulmanes los viernes no se trabaja, en 
los cristianos el domingo) hacen de esta experiencia un reto en todos los sentidos

Por último, una reflexión de carácter más personal: el conocer la realidad detrás de cada alumno, su historia de lucha por la supervivencia y superación y las situaciones pasadas por cada uno hace que la tarea educativa cobre todo su sentido. 